\title{
Produção de vídeos institucionais dos Geoparques Caçapava do Sul e Quarta Colônia: uma experiência em audiovisual
}

\author{
Aline Roes Dalmolin \\ aline.dalmolin@ufsm.br \\ Francys Albrecht da Rosa \\ franalbrecht13@gmail.com
}

\section{Resumo}

O texto relata a experiência da produção de vídeos institucionais sobre os Geoparques Caçapava do Sul e da Quarta Colônia através de um projeto de ensino e extensão da Universidade Federal de Santa Maria (UFSM). A realização dos vídeos envolveu a imersão dos alunos de produção audiovisual do curso de Comunicação Social - Produção Editorial no patrimônio e nos espaços geográficos dos geoparques, atuando nas etapas de pré-produção, produção e pós-produção audiovisual. A ação produziu um conjunto de seis vídeos, utilizados como material de divulgação e de apoio no sentido de credenciar os espaços dos Geoparques Caçapava e da Quarta Colônia à obtenção da chancela da Unesco.

\section{Palavras-chave}

Produção audiovisual; geoparques; vídeo institucional. 


\section{Introdução}

O presente texto traz um relato de experiência de um projeto de ensino e extensão já finalizados, voltado à elaboração de vídeos institucionais sobre os Geoparques Caçapava do Sul e da Quarta Colônia, no âmbito da disciplina de Produção Audiovisual do curso de Comunicação Social - Produção Editorial da Universidade Federal de Santa Maria (UFSM). A atividade de extensão, realizada durante o primeiro semestre de 2019, soma-se aos esforços iniciados pela Universidade Federal de Santa Maria em 2018, através de sua Pró-Reitoria de Extensão, de incentivar e articular a criação de dois geoparques na região central do Rio Grande do Sul, fomentando essa ação junto a suas respectivas comunidades e à sociedade como um todo.

Os geoparques consistem em "territórios reconhecidos pela Unesco em que a 'Memória da Terra' é preservada e utilizada de forma sustentável para gerar desenvolvimento para a sua comunidade" (UFSM, s/data, online), que se dá através de atividades econômicas que visam a preservação do patrimônio e da cultura das comunidades. Existem, ao todo, 147 Geoparques Mundiais da Unesco, em 41 países, sendo apenas um deles localizado no Brasil: o Geoparque Araripe, que fica no interior do Ceará.

Na região central do Rio Grande do Sul, duas regiões apresentam condições para serem reconhecidas com o título pela Unesco. 0 município de Caçapava do Sul destaca-se por abrigar rochas sedimentares bastante antigas, com mais de 500 milhões de anos, expostas em pontos turísticos reconhecidos como as Pedras das Guaritas e a Serra do Segredo, além de fósseis únicos de animais extintos da megafauna como a preguiça-gigante. Já o conjunto de pequenos municípios que agregam a região conhecida como Quarta Colônia - Silveira Martins, Ivorá, Faxinal do Soturno, São João do Polêsine, Dona Francisca, Nova Palma, Pinhal Grande e Restinga Seca - reúne um considerável patrimônio fossilífero de mais de 150 milhões de anos, belezas naturais e o patrimônio imaterial da cultura de imigração italiana e alemã (UFSM, s/data).

Ao todo foram produzidos seis vídeos institucionais sobre os projetos, sendo três com foco no projeto Geoparque Caçapava do Sul e outros três sobre o Projeto Geoparques Quarta Colônia. Dos seis, foi escolhido um vídeo sobre cada um dos geoparques em questão para servir de apoio para divulgação dos projetos, no sentido de credenciar ambos os espaços obtenção da chancela da Unesco. A produção dos vídeos ocorreu no primeiro semestre letivo de 2019, com a participação de todos os alunos do curso de Comunicação Social - Produção Editorial matriculados na disciplina Produção Audiovisual, que aceitaram também participar do projeto de extensão. 
A disciplina em questão tem por intuito introduzir os alunos no universo da produção audiovisual, trazendo seus principais elementos e relacionando-os ao campo de atuação do futuro profissional. Em um semestre, os estudantes trabalham os fundamentos do audiovisual, que remontam a sua fixação enquanto arte e linguagem, com raízes no cinema, na fotografia, na pintura, no teatro, entre outros. Os alunos participam de aulas práticas e tomam contato com ferramentas profissionais de produção, em exercícios que auxiliam os estudantes a perder o receio de "pôr as mãos na massa", ou seja, literalmente, operar os equipamentos profissionais de gravação. Em aula, os estudantes realizam práticas como gravação audiovisual em estúdio e ao ar livre, resolvem problemas comuns em produção, redigem roteiros, planejam gravações, editam vídeos, ou seja, exercitam todas as etapas da produção audiovisual, da pré à pósprodução (AUTOR 1, no prelo).

No decorrer do primeiro semestre de 2019, estas práticas se deram, portanto, no espaço geográfico de Caçapava do Sul e da Quarta Colônia, e de forma intensamente articulada ao Projeto Estratégico Geoparque. Mais do que fonte das informações necessárias para a realização dos vídeos, estudantes, docentes e técnico-administrativos associados a este projeto participaram de forma ativa das produções. Estes também forneceram consultoria durante todas as etapas de produção dos vídeos, e foram os responsáveis para, juntamente com a equipe da Pró-Reitoria de Extensão da UFSM, em definir quais dos vídeos produzidos seriam utilizados para a divulgação dos Geoparques. Ressalta-se que essa espécie de "concurso" também serviu de incentivo para os estudantes dedicarem-se com afinco à execução dos vídeos, sobretudo com a possibilidade de este vir a ser reconhecido internacionalmente no âmbito do reconhecimento daqueles espaços.

\section{Relato de experiência}

Após uma série de reuniões iniciais, constituiu-se a equipe de coordenação do projeto, composta pela professora da disciplina e coordenadora do projeto de extensão "Produção de vídeos institucionais dos Geoparques Caçapava do Sul e Quarta Colônia", por docentes participantes do projeto Geoparques e pela coordenadora da ação na Pró-Reitoria de Extensão da UFSM. Desde o primeiro momento, esta instância institucional se responsabilizou por dar todo o apoio logístico às ações, organizando as idas a campo. Esta participação foi legitimada pela classificação deste projeto na CHAMADA PÚBLICA 04/2019/PRE Geoparques, um edital 
interno da UFSM que contemplou com recursos projetos institucionais associados a este projeto maior, caso do projeto de extensão em questão. Com isso, o presente projeto foi um dos 17 contemplados em 2019 através deste edital, e a totalidade dos recursos foi destinada para custear as idas a campo dos alunos e equipe de coordenação do projeto.

O semestre iniciou no dia 18 de março de 2019, com a proposição da atividade para os alunos da disciplina de Produção Audiovisual, uma vez que esta se daria de forma inaugural nos moldes da disciplina. Em anos anteriores, os alunos realizavam como trabalho final vídeos em formato livre, e havia uma certa expectativa destes em realizar trabalho similar. Portanto, alguns dos estudantes se surpreenderam com a proposição dos vídeos institucionais como objetivo da disciplina. Um conjunto expressivo de alunos mostraram-se inicialmente refratários à ideia, o que pode ter ocorrido em decorrência desta quebra de expectativas. Em relatório elaborado no final do semestre, o estudante W. reflete sobre essa situação ${ }^{1}$.

Inicialmente eu relutei para gostar da ideia, eu tinha expectativa de poder criar um roteiro do zero. Eu entendo que isso possui muitos problemas e trabalho dobrado, acaba não sendo padronizado. Além do mais, é importante que nós saibamos como produzir um vídeo institucional profissional, é isso que o mercado de trabalho vai nos exigir. Depois de conhecer os locais e ver o resultado do nosso vídeo eu fico contemplado de ter participado da disciplina e do projeto dos geoparques, com certeza é um dos meus orgulhos da faculdade. (W., participante do projeto)

Uma estratégia para engajar os alunos foi realizar uma apresentação do projeto. Em um dos encontros iniciais da disciplina, em participação especial, professores do Departamento de Geociências apresentaram a proposta dos Geoparques da Quarta Colônia e Caçapava do Sul. A seguir, os estudantes foram divididos em seis grupos, e cada grupo teve sorteado o espaço de geoparque que o vídeo tematizaria, resultando em três grupos com o tema Quarta Colônia e outros três com o tema Caçapava do Sul. A produção dos vídeos se deu de acordo com as etapas de produção audiovisual: pré-produção, produção e pós-produção (ZETTL,2011).

No decorrer dos meses de março e abril, os estudantes seguiram o desenvolvimento do plano de ensino da disciplina, em aulas expositivas sobre os fundamentos da linguagem audiovisual, escolas e períodos do cinema e demais aspectos técnicos e teóricos envolvendo a produção de vídeos. Entre abril e junho, os alunos participaram de oficinas práticas no campus da UFSM, nas quais desenvolveram competências técnicas para a operação de equipamentos

1 Ao final da disciplina, os estudantes elaboraram relatório sobre as atividades desenvolvidas (AUTOR 1, 2020). Todos os depoimentos dos alunos constantes neste artigo consistem nas respostas deles à pergunta, constante no modelo do relatório, "Como você avalia a realização da disciplina em conjunto com o projeto Geoparques?” Por motivos éticos, a identificação de todos os estudantes foi preservada. 
audiovisuais e realizaram gravações curtas, a fim de que, na ocasião das idas a campo, os estudantes já tivessem um mínimo de domínio das ferramentas profissionais de gravação.

Concomitantemente às atividades de ensino no âmbito da disciplina, em março e abril, a equipe de coordenação trabalhou no desenho do circuito dos pontos de interesse turístico, geológico, histórico e cultural a serem enfatizados nos vídeos. Foram desenvolvidos dois roteiros de visitação, contemplando os dois Geoparques, a serem cumpridos em dois dias inteiros pelos estudantes em cada um destes espaços (FIGURAS 2 e 3). Os resultados das pesquisas e projetos de extensão dos professores e estudantes que fazem parte do projeto Geoparques proporcionaram aos estudantes as informações necessárias para a realização dos vídeos, como os trabalhos de Zieman (2016), Cechin (2019), Borba (2017) e Borba et alii $(2013,2016)$.

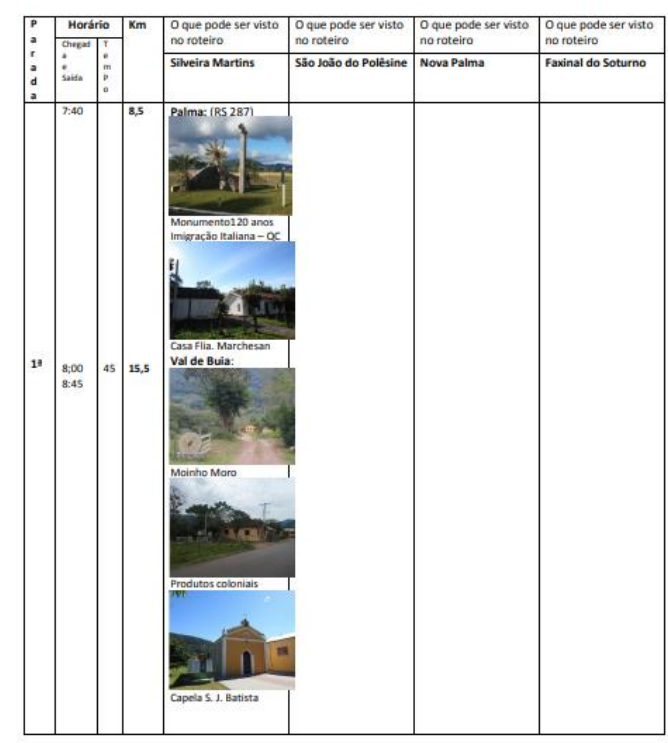

Roteiro de visitação para filmagens em Caçapava do Sul no dia 20/5, segunda-feira:

$7.00 \mathrm{~h}$ - saida do campus UFSM; $7.30 \mathrm{~h}$ - saida da Catedral

$9.00 \mathrm{~h}$ - Unipampa, jardim da geodiversidade $\mathrm{d} /$ preguiça-gigante;

10.00h - Forte Dom Pedro II, muralhas (possibilidade interessante de uso de drone);

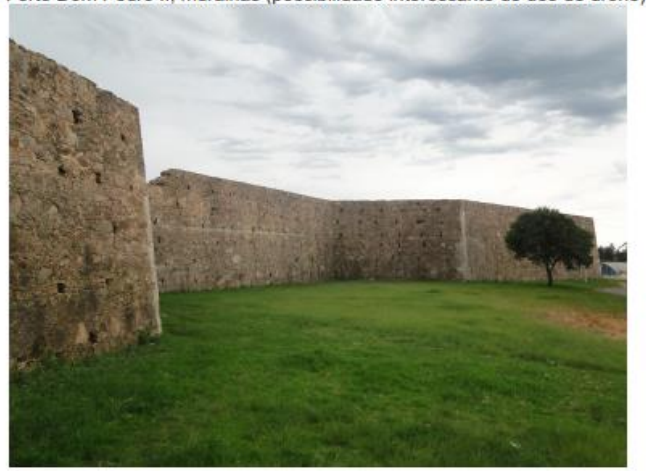

Figuras 2 e 3: Detalhe dos roteiros de visitação dos Geoparques Quarta Colônia e Caçapava do Sul. Fonte: elaborados por André Borba e Dilson Cechin (apud AUTOR 1, 2020).

A partir desses roteiros, os estudantes trabalharam na pré-produção (pesquisa, definição dos planos e roteiro técnico). Uma das principais dificuldades elencadas pelos alunos foi a de terem de elaborar os roteiros técnicos antes mesmo de visitarem os espaços, uma vez que nas viagens de campo eles teriam de captar as imagens. Contudo, eles ressaltam que justamente a diversidade dos espaços representou um fator de crescimento no aprendizado dos estudantes.

(...) por ser um projeto que não costuma ser desenvolvido na disciplina, acredito que a oportunidade de um trabalho em campo fora do município no qual estamos acostumados permitiu uma experiência produtiva para os graduandos, ainda que o fato de muitos não conhecerem os locais de gravação tenha dificultado um pouco o desenvolvimento dos vídeos. (A., participante do projeto). 
Acredito que foi uma experiência bastante significativa, pois se tivéssemos feito outro tipo de trabalho final para a disciplina, como por exemplo um curta de tema livre, provavelmente não aprenderíamos tanto sobre pré-produção, produção e pós-produção como aprendemos realizando o projeto Geoparques. As nossas idas a campo fizeram com que trabalhássemos com algo novo, desafiador e real, além de ter gerado a oportunidade de conhecermos lugares onde nunca tínhamos estado antes. (L., participante do projeto).

A etapa de produção se deu durante os meses de maio e junho. As gravações se deram em Caçapava do Sul, Silveira Martins, Ivorá, Faxinal do Soturno, São João do Polêsine, Nova Palma, Pinhal Grande. Não foram abrangidos os municípios de Dona Francisca e Restinga Seca, que também fazem parte da região da Quarta Colônia, em função do tempo disponível para as gravações, o que não chegou a comprometer o resultado final. As idas a campo consistiram em viagens de estudo de um dia inteiro (FIGURAS 4 e 5), sob coordenação dos professores e estudantes participantes do projeto Geoparques, que ocorreram de acordo com o seguinte cronograma e roteiro de visitação dos pontos de interesse:

20 de maio de 2019 - Geoparque Caçapava do Sul (Centro Histórico, Chácara do Forte e Pedra do Segredo)

10 de junho de 2019 - Geoparque Quarta Colônia - Silveira Martins (Monumento do Imigrante, Centro Histórico, Complexo da Pompeia), São João do Polêsine (Vale Vêneto e Centro de Apoio à Pesquisa Paleontológica da Quarta Colônia - Cappa), Nova Palma (Cascata do Pingo e Centro Histórico).

17 de junho de 2019 - Geoparque Quarta Colônia - Pinhal Grande (Paga Peão e Usina de Itaúba) e Faxinal do Soturno (Museu Municipal e Ermida São Pio)

18 de junho de 2019 - Geoparque Caçapava do Sul (Minas do Camaquã e Guaritas)

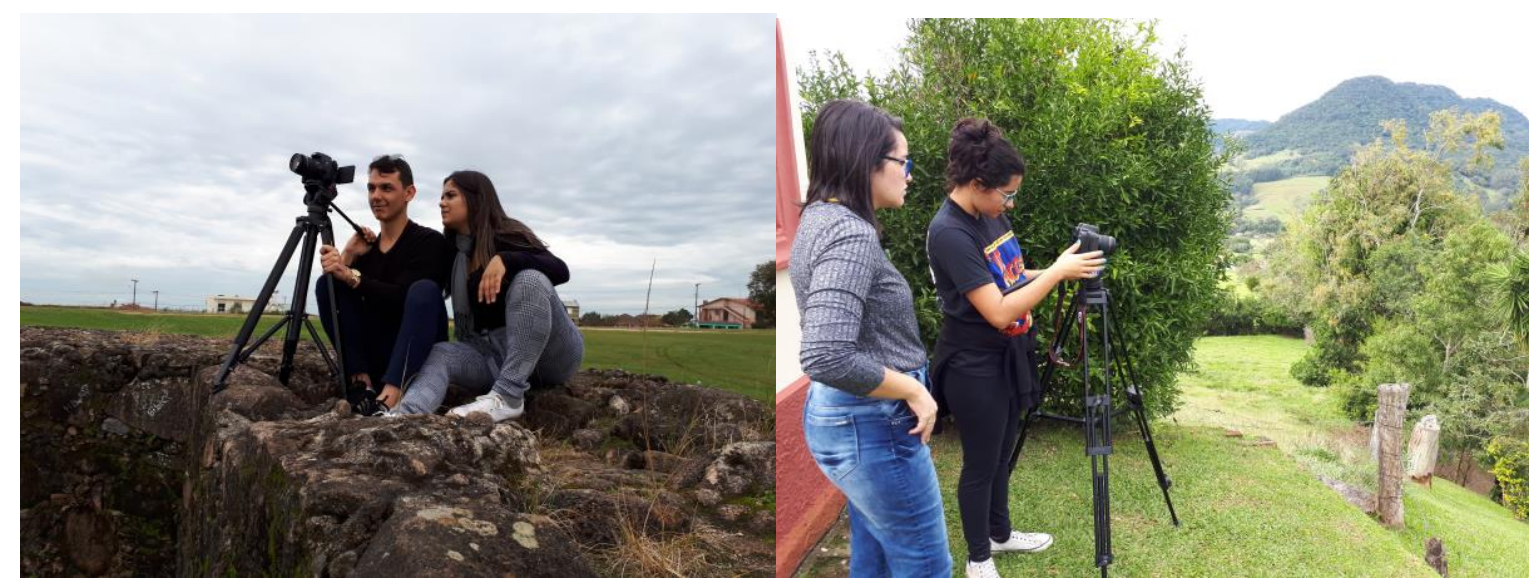

Figuras 4 e 5: Fotos das gravações nos Geoparques Caçapava do Sul e Quarta Colônia

Fonte: foto das autoras, acervo pessoal. 
Nas idas a campo, os estudantes desenvolviam práticas que exercitavam os conhecimentos teóricos aprendidos em sala de aula, como enquadramento, exposição, entre outros, ao mesmo tempo que se aproximavam das comunidades, foco da ação. Alguns dos participantes eram originários daqueles espaços geográficos, e se surpreendiam ao reconhecer as belezas naturais e atrativos geológicos em seus territórios de origem, enquanto outros, oriundos de outros espaços e inclusive outros estados do país, ficavam ainda mais surpresos em conhecer os territórios.

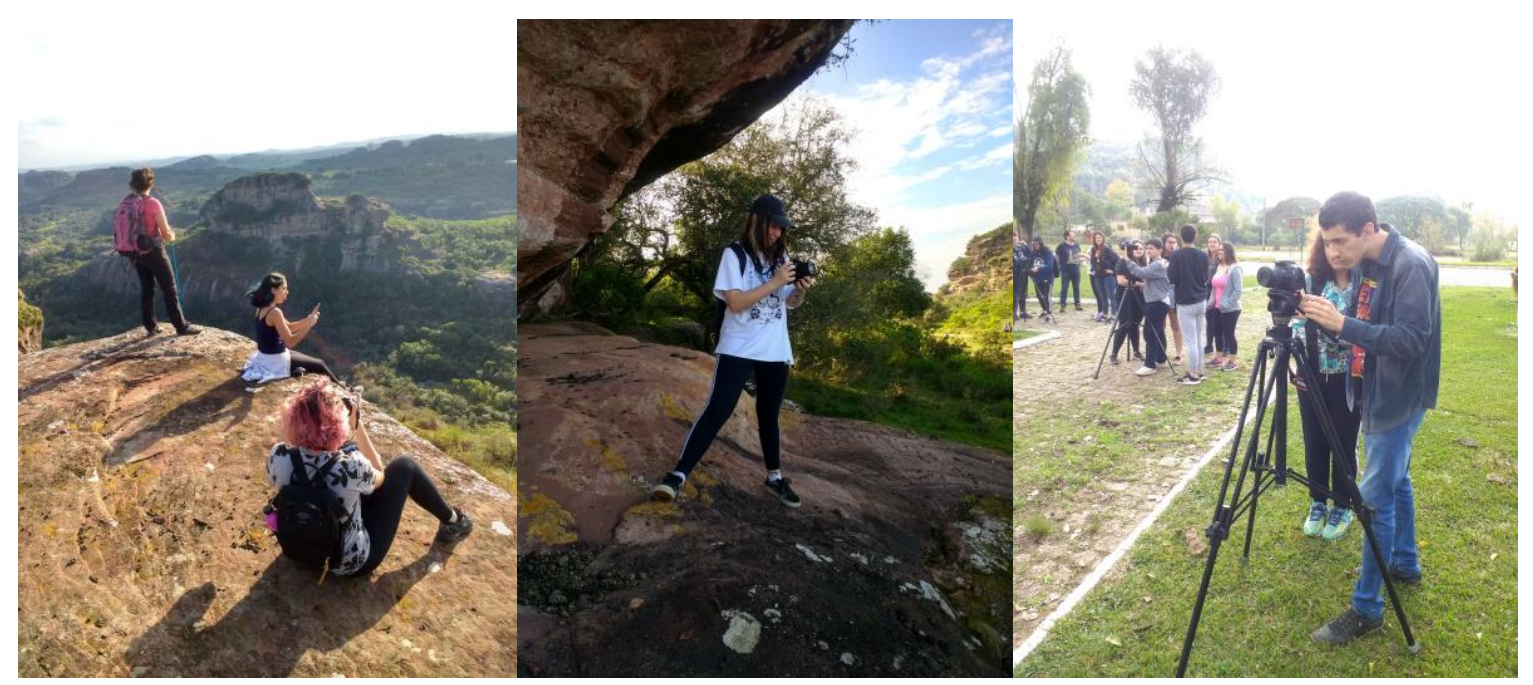

Figuras 6, 7 e 8: Fotos das gravações nos Geoparques Caçapava do Sul. Fonte: foto das autoras, acervo pessoal.

Aos poucos, o olhar da câmera ia estruturando uma narrativa, ao mesmo tempo deslumbrada e que promovia reconhecimento das comunidades que circundam o ambiente universitário e das outras áreas do conhecimento que o compõem através de sua interdisciplinaridade. Além do espaço físico, os alunos puderam conhecer e se envolver com o aspecto cultural e humano das localidades.

Acredito que a união da disciplina com o projeto Geoparques possibilitou aos alunos experiências diferentes das que eram propostas nas versões anteriores da matéria. Dessa forma, os alunos tiveram mais contato com as fases de préprodução, produção e pós-produção de maneira mais abrangente e criativa. Além disso, tivemos a oportunidade de conhecer novos lugares, assim, além de levarmos conosco os conteúdos aprendidos, poderemos levar as vivências e os conhecimentos obtidos durante as visitas realizadas. (M., participante do projeto). 
Foi muito interessante pois o projeto é de cunho interdisciplinar e envolveu conhecimentos da geografia e relevo, além disso, pode-se colocar os conhecimentos prévios de audiovisual passados em aula junto da natureza. (A., participante do projeto)

Acredito que essa disciplina fornece bastante material teórico e em conjunto com o projeto geoparque essa teoria pode ser colocada em prática. Da forma que foi mesclada com o projeto pode se ter um aproveitamento maior em quesito de comprometimento, pois a produção desse material pede por uma postura madura e responsável, o que faz com que os alunos se empenhem mais. Esse empenho promove a participação dos alunos em todas as etapas de criação e concepção do vídeo final. (A., participante do projeto)

Após a captura das imagens, seguiu-se a etapa de pós-produção, que consistiu na decupagem, edição e tratamento das imagens capturadas, que ocorreu no Laboratório Estúdio 21, no Campus Sede da UFSM. Seguiu-se a inserção de lettering, efeitos sonoros, cortes e trilha sonora nos vídeos. Destaca-se em relação ao lettering o alinhamento com os aspectos gráficos constantes nas respectivas marcas elaboradas de cada projeto, possibilitada com a utilização dos manuais de marca dos Geoparques Quarta Colônia e Caçapava do Sul. Já em relação ao material sonoro, priorizou-se a utilização de material oriundo de bibliotecas de uso livre, com licenças Creative Commons, por permitirem o uso por iniciativas como esta sem fins lucrativos.

Após a finalização dos seis vídeos produzidos na disciplina, estes foram exibidos no último dia de aula da disciplina, no Auditório do Centro de Ciências Naturais e Humanas da UFSM, com a participação da equipe coordenadora do projeto Geoparques, em sessão aberta para o público em geral. Após a exibição, a equipe coordenadora reuniu-se para definir os vídeos eleitos para representar o Geoparque Quarta Colônia (FIGURAS 9 e 10) e o Geoparque Caçapava do Sul (FIGURAS 11 e 12).
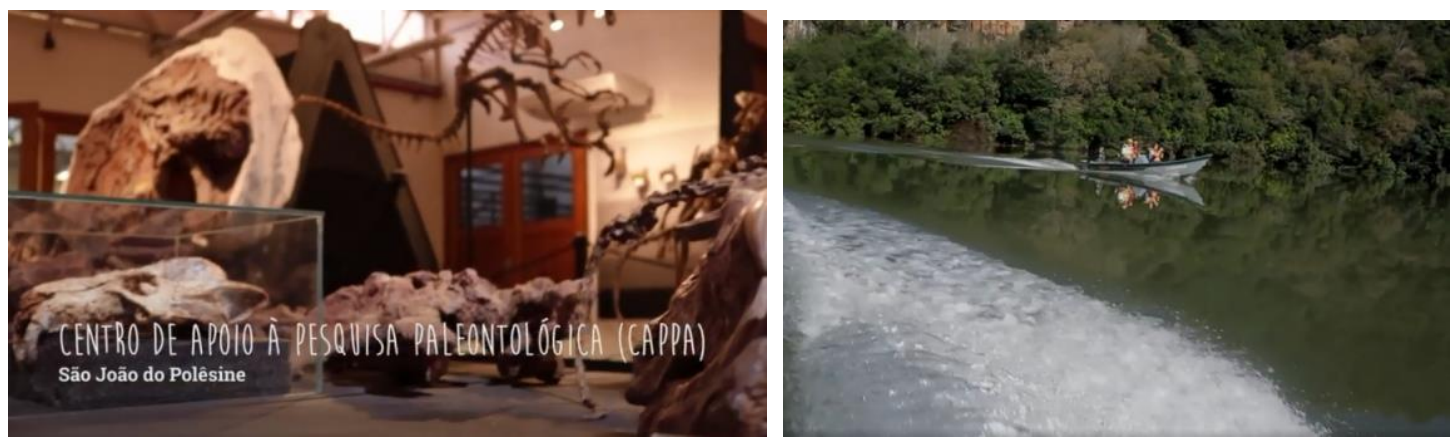

Figuras 9 e 10: Stills dos vídeos Geoparque Quarta Colônia Fonte: UFSM (2019a). 

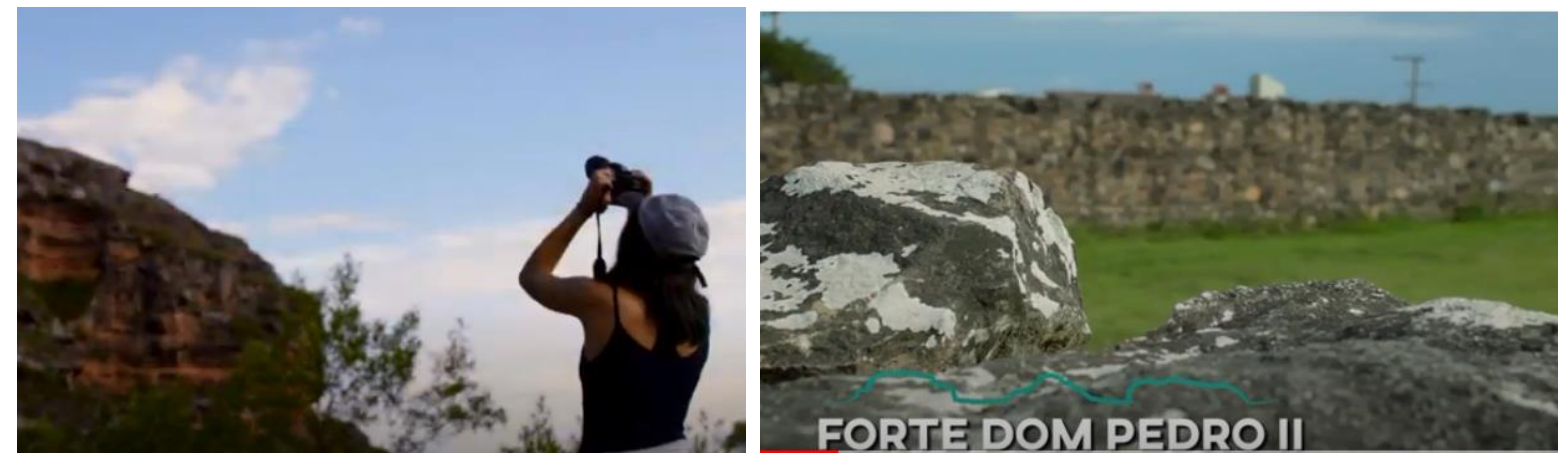

Figuras 11 e 12: Stills dos vídeos Geoparque Caçapava do Sul Fonte: UFSM (2019b).

Além disso, o vídeo eleito para representar o Geoparque Quarta Colônia foi exibido também durante a programação do Festival Internacional de Inverno da UFSM, em Vale Vêneto (Figura 13)., com presença de mais de 700 pessoas no local de exibição do vídeo (UFSM, 2019c). O Festival de Inverno é um evento anual promovido pela UFSM em parceria com a comunidade de Vale Vêneto, um dos eventos mais importantes de extensão da Universidade e da Quarta Colônia. No evento, também ocorreu o lançamento da logomarca do Geoparque Quarta Colônia. Ambos os vídeos constam, atualmente, no material oficial da UFSM de divulgação dos projetos.

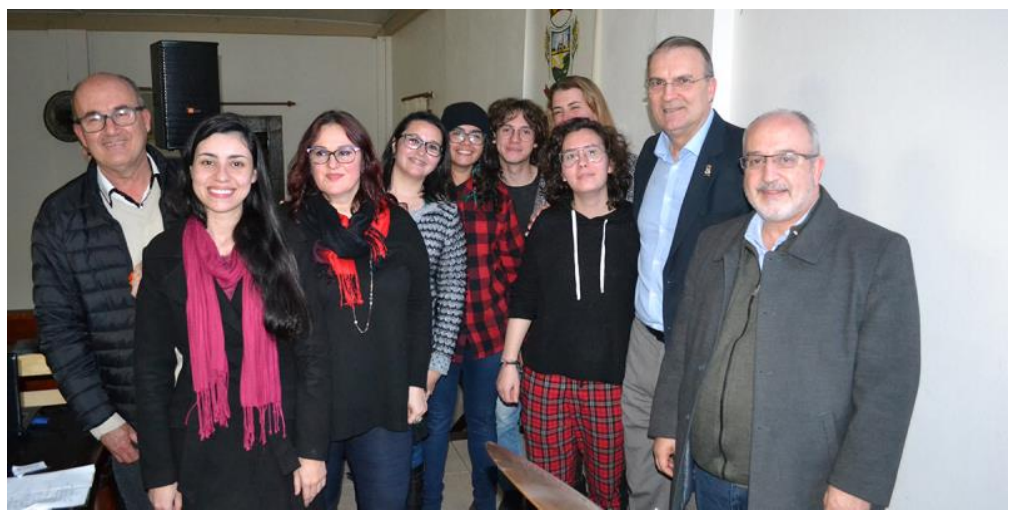

Figura 13: Autoridades, professores e estudantes após apresentação do vídeo Geoparque Quarta Colônia (UFSM, 2019b) em Vale Vêneto, durante o Festival Internacional no dia 2 de agosto de 2019.

Fonte: INTEGRAÇÃO, 2019.

Os momentos de exibição e o relatório final realizado no âmbito da disciplina representaram instâncias importantes de reconhecimento dos alunos sobre suas participações no projeto de extensão, nas quais foi possível realizar um balanço do processo realizado e ponderar de forma crítica sobre sua realização. No relatório final, os alunos avaliaram a 
realização do vídeo e a participação na atividade extensionista, que envolveu uma forte interação com as comunidades envolvidas.

Acredito que tenha sido uma atividade válida, que se relaciona com as tarefas e procedimentos a serem cumpridos no mercado de trabalho, uma vez que existe um briefing pré-determinado, e é preciso atender às necessidades da instituição. Além disso, participar do projeto foi uma experiência interessante, que permitiu o contato com a região de Caçapava do Sul e com seus principais pontos. (T., participante do projeto)

A disciplina de audiovisual foi muito gratificante na minha experiência, como não tinha contato com audiovisual, foi de muito aprendizado. Com esse projeto, podemos aprender tanto a edição como realizar a parte mais burocrática de um vídeo institucional, o projeto foi muito legal e as pessoas compostas por ele muito atenciosas, é bacana aprender com um projeto mais institucional, pois só tivemos projetos mais voltados a universidade e ao dia a dia. (Y., participante do projeto)

A disciplina foi muito boa, porém esse projeto acabou exigindo bastante de nós, principalmente que tivemos que ir gravar em locais que muitos nunca foram. Mas é muito legal saber que pudemos contribuir para um projeto maior da Universidade. A disciplina foi muito boa. A mistura de teóricas e práticas funciona bem, principalmente porque algumas questões só aprendemos mesmo quando vamos pôr a mão na massa, além de que separar a turma também ajudou para ter um melhor aproveitamento das aulas práticas, visto que não há equipamento para todos. Por mais que não fosse o que eu esperava, a participação no Projeto Geoparques acabou sendo algo interessante e de grande aprendizado. (0., participante do projeto)

Com isso, obteve-se, a partir dos vídeos, algo mais complexo que um mero material ilustrativo, mas um produto de extensão estrategicamente articulado às ações desenvolvidas no âmbito do Projeto Estratégico Institucional Geoparques, sintonizando aspectos da pesquisa, do ensino e da extensão universitárias. Os vídeos finais podem ser acessados a partir dos links presentes na tabela abaixo (Tabela 1).

\begin{tabular}{|l|l|l|}
\hline Título do vídeo & Duração & Link do vídeo \\
\hline Vídeo Geoparque Caçapava do Sul 1 & 2'54" & https://www.youtube.com/watch?v=Y27JxZq1vs0 \\
\hline Vídeo Geoparque Caçapava do Sul 2 & 3'11" & https://youtu.be/ALkFh8UJQRc \\
\hline Vídeo Geoparque Caçapava do Sul 3 & 2'36" & https://youtu.be/_-DVxPTZ_DY \\
\hline Vídeo Geoparque Quarta Colônia 1 & 3'52" & https://youtu.be/-ZMYGurCnBI \\
\hline Vídeo Geoparque Quarta Colônia 2 & 2'30" & https://youtu.be/cEOvw7M7p-c \\
\hline Vídeo Geoparque Quarta Colônia 3 & 3'52" & https://youtu.be/YtXY9YKvPUs \\
\hline
\end{tabular}

Tabela 1: Links para os vídeos finais produzidos pelos estudantes.

Fonte: elaboração das autoras. 
Um dos aspectos a ser destacado para a realização deste projeto foi a parceria com o laboratório didático Estúdio 21, do Departamento de Ciências da Comunicação da UFSM, que disponibilizou sua estrutura física, equipamentos e recursos humanos para dar apoio às práticas de audiovisual. Neste trabalho, destaca-se a participação de seus técnicos-administrativos em educação que auxiliaram os alunos nas práticas audiovisuais do projeto, atuando como apoio técnico, sobretudo em relação ao manuseio do equipamento, acompanhando e orientando os alunos nas etapas de produção audiovisual. Igualmente importante foi a participação da mestranda do Programa de Pós-Graduação em Comunicação da UFSM, que atuou como estagiária docente na disciplina, atuando como apoio em todas as etapas da produção audiovisual, articulando os conhecimentos da graduação e pós-graduação.

\section{Considerações finais}

Ao contrário do que a aparente apatia inicial poderia indicar, os resultados finais deste projeto apontam para uma percepção totalmente positiva dos estudantes a respeito de sua participação. O envolvimento dos estudantes de Comunicação Social- Produção Editorial no decorrer do semestre ofereceu uma oportunidade única em sua formação, de participar de um projeto de tal envergadura em uma atividade envolvendo ensino e extensão. A partir da participação em uma disciplina, eles puderam desenvolver um material que pode alcançar suas comunidades, perfazendo os sentidos da extensão, ao mesmo tempo que os estudantes realizaram sua formação através de disciplinas práticas, consolidando suas finalidades de ensino. Além disso, há a possibilidade de divulgação internacional, na medida em que os geoparques consigam consolidar a sua proposta. Desse modo, o projeto auxilia os alunos a não apenas atingir os objetivos da disciplina, que é a capacitação técnica na área audiovisual, mas associá-los aos objetivos da extensão de reforçar os laços com a comunidade e o compromisso social da Universidade com os espaços que a circundam, como reforça a estudante A.: 


\begin{abstract}
Gostei muito de fazer o trabalho em conjunto com este projeto tão interessante e que não fazíamos ideia que existisse antes da disciplina, acho que ambas as partes agregaram uma a outra, tanto nós, alunos da disciplina, que precisávamos testar nossas habilidades enquanto acadêmicos de audiovisual diante de qualquer tipo de gravação ou roteiro que aparecesse, nós precisávamos dar o nosso melhor e abraçar a causa, quanto o pessoal do projeto que necessitava desse apoio de pessoas dispostas a fazer acontecer o que nos foi proposto para que pudessem mostrar a riqueza e a diversidade que os lugares (Caçapava e Quarta Colônia) apresentam e são pouco conhecidos no geral. A união da disciplina com o projeto, com certeza agregou muito para mim e acho que para toda turma também, pois foi um desafio que nos fez aprender algumas técnicas e a lidar com situações adversas que possam aparecer durante a pré-produção, produção e, principalmente, a pós-produção, que se fez como o maior desafio, que com bastante esforço, conseguiu ser concluída. (A, participante do projeto).
\end{abstract}

A interdisciplinaridade e a interprofissionalidade, aspectos importantes nas práticas de extensão, foi reforçada pela aproximação dos participantes com estes diferentes universos, através das diferentes áreas do conhecimento que constituem o Projeto Estratégico Geoparques, alicerçando a indissociabilidade entre ensino, pesquisa e extensão. Por outro lado, a realização do projeto apresenta uma configuração bastante similar a qual os alunos irão encontrar no mercado de trabalho, que é a necessidade de adequar um produto audiovisual aos objetivos estratégicos de um cliente, organização ou instituição.

Destaca-se a interface com as comunidades envolvidas, que podem ver no projeto um apoio para suas ações locais, consistindo na finalidade última do foco extensionista, promovendo uma relação dialógica entre o estudante e a sociedade, o que representa um impacto importante em sua formação. Esta ação se dá com o comprometimento do projeto com um dos desafios do Plano de Desenvolvimento Institucional (PDI) 2016-2016 (UFSM, 2016), que se dá no esforço da Universidade atuar para o desenvolvimento local, regional e nacional.

Para edições futuras do projeto ou realizações similares, cogita-se aplicar as ações com alunos mais adiantados em relação ao aprendizado das técnicas de produção audiovisual e ao próprio curso. Isso faz dos aprendizados obtidos a partir dessa iniciativa uma experiência interessante para repensar as práticas curriculares de ensino e a própria curricularização da extensão em comunicação e audiovisual, de forma a auxiliar com suas técnicas a execução de projetos de outras áreas, em perspectiva inter e transdisciplinar.

\title{
Referências
}

AUTOR 1. A formação em audiovisual no curso de Comunicação Social-Produção Editorial da UFSM. Revista 0 QI. (no prelo). 
AUTOR 1. Relatório final do projeto "Produção de vídeos institucionais dos Geoparques Caçapava do Sul e Quarta Colônia”. Santa Maria: UFSM, 2020.

BORBA, André W. de. Geomonumentos de Caçapava do Sul (Centro-sul do RS, Brasil) e seu destaque na paisagem: a quantificação do valor estético do geopatrimônio e suas aplicações. Geografia Ensino \& Pesquisa. V. 21, N. 1, jan/abr (2017).

BORBA, André Weissheimer de, SOUZA, Luiz Fernando de, MIZUSAKI, Ana Maria Pimentel, ALMEIDA, Delia del Pilar Montecinos de, STUMPF, Paola Prates. "Inventário e avaliação quantitativa de geossítios: exemplo de aplicação ao patrimônio geológico do município de Caçapava do Sul (RS, Brasil)". Pesquisas em Geociências, v. 40, n. 3, p. 275-294, 2013.

BORBA, André Weissheimer de, SILVA, Elisângela Lopes da, SOUZA, Luiz Paulo Martins, SOUZA, Luiz Fernando de, MARQUES, Rosane Vera. "Relação entre a geodiversidade intrínseca e a estruturação de habitat na escala do geossítio: exemplos na Serra do Segredo e nas Pedras das Guaritas (Caçapava do Sul, RS, Brasil)". Pesquisas em Geociências, v. 43, n. 2, p. 183-202, 2016.

CECHIN, Dilson N. Integração do patrimônio natural ao cultural como recurso geoturístico na implantação do projeto do geoparque Quarta Colônia, RS, Brasil. Tese (Doutorado). Universidade Federal de Santa Maria, Programa de Pós-Graduação em Geografia e Geociências, Santa Maria, 2019.

INTEGRAÇÃO Rádio e Jornal. Nova marca do projeto Geoparque Quarta Colônia representa características marcantes do território. 2 agosto 2019, Disponível em:

http://radiojornalintegracao.com.br/nova-marca-do-projeto-geoparque-quarta-coloniarepresenta-caracteristicas-marcantes-do-territorio/ . Acesso em 29 set 2020.

UFSM. Projeto Geoparques, 2019. Disponível em: <https://www.ufsm.br/proreitorias/pre/geoparques/>. Acesso em 16 set. 2019.

UFSM Universidade Federal de Santa Maria. Plano de Desenvolvimento Institucional (PDI) 2016-2026. Santa Maria: Universidade Federal de Santa Maria, 2016. Disponível em: https://www.ufsm.br/app/uploads/sites/500/2018/12/00-DocumentoPDITextoBaseCONSU.pdf. Acesso em 29 set 2020.

UFSM, Universidade Federal de Santa Maria. Vídeo institucional do Geoparque Quarta Colônia. 2019a Disponível em: <https://www.facebook.com/geoparquequartacolonia/videos/383253848905750/. $>$. Acesso em 29 set 2020.

UFSM, Universidade Federal de Santa Maria. Vídeo institucional do Geoparque Caçapava do Sul. 2019b Disponível em: < https://www.youtube.com/watch?v=Y27JxZq1vs0 >. Acesso em 29 set 2020.

UFSM, Universidade Federal de Santa Maria. Pró-Reitoria de Extensão. Relatório do Projeto Geoparque Quarta Colônia 2019. 2019c Disponível em: < https://www.ufsm.br/app/uploads/sites/346/2020/06/Relat\%C3\%B3rio-18-19-e-I.20GQC.pdf>. Acesso em 29 set 2020.

ZETTL, Herbert. Manual de produção de televisão. São Paulo: Cengage Learning, 2011. 
ZIEMAN, Djulia. Estratégias de Geoconservação para a proposta de Geoparque da Quarta Colônia-RS. Dissertação (Mestrado). Universidade Federal de Santa Maria, Programa de PósGraduação em Geografia e Geociências, Santa Maria, 2016. 


\section{Geoparks Caçapava do Sul and Quarta Colônia's institucional videos production: an audiovisual experience report}

\begin{abstract}
The text reports the producing institutional videos experience, envolving Caçapava do Sul and Quarta Colônia Geoparks, through a teaching and extension project at the Universidade Federal de Santa Maria (UFSM). The making involved the immersion of audiovisual production students in the Social Communication - Editorial Production course in the heritage and geographic spaces of the geoparks, working in the stages of preproduction, production and audiovisual postproduction. The action produced a set of six videos, used as promotional and support material in order to accredit Caçapava and Quarta Colônia Geoparks with Unesco's recognition.
\end{abstract}

\section{Keywords}

Audiovisual production; geoparks; institutional video.
Producción de videos institucionales de los Geoparques Caçapava do Sul y Quarta Colônia: un relato de experiencia audiovisual

\section{Resumen}

El texto relata la experiencia de producir videos institucionales sobre los Geoparques Caçapava do Sul y Quarta Colônia a través de un proyecto de docencia y extensión en la Universidade Federal de Santa María (UFSM). La realización de los videos supuso la inmersión de los estudiantes de producción audiovisual en la carrera Comunicación Social - Producción Editorial en el patrimonio y los espacios geográficos de los geoparques, trabajando en las etapas de preproducción, producción y postproducción audiovisual. La acción produjo un conjunto de seis videos, utilizados como material promocional y de apoyo con el fin de acreditar los espacios de los Geoparques Caçapava y Quarta Colônia con el sello de la Unesco.

\section{Palabras clave}

Producción audiovisual, geoparques, video institucional. 